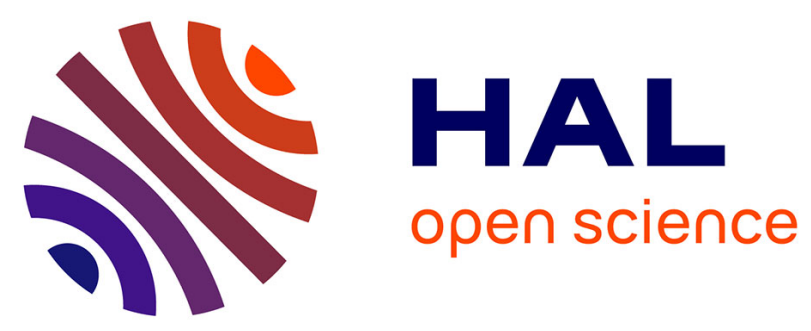

\title{
Impact of bariatric surgery on apolipoprotein C-III levels and lipoprotein distribution in obese human subjects
}

\author{
Marie Maraninchi, Nadege Padilla, Sophie Béliard, Bruno Berthet, \\ Juan-Patricio Nogueira, Jeanine Dupont-Roussel, Julien Mancini, Audrey \\ Bégu-Le Corroller, Noémie Dubois, Rachel Grangeot, et al.
}

\section{To cite this version:}

Marie Maraninchi, Nadege Padilla, Sophie Béliard, Bruno Berthet, Juan-Patricio Nogueira, et al.. Impact of bariatric surgery on apolipoprotein C-III levels and lipoprotein distribution in obese human subjects. Journal of clinical lipidology, 2017, 11 (2), pp.495 - 506.e3. 10.1016/j.jacl.2017.02.012 . hal-01757597

\section{HAL Id: hal-01757597 \\ https://hal-amu.archives-ouvertes.fr/hal-01757597}

Submitted on 10 Apr 2018

HAL is a multi-disciplinary open access archive for the deposit and dissemination of scientific research documents, whether they are published or not. The documents may come from teaching and research institutions in France or abroad, or from public or private research centers.
L'archive ouverte pluridisciplinaire HAL, est destinée au dépôt et à la diffusion de documents scientifiques de niveau recherche, publiés ou non, émanant des établissements d'enseignement et de recherche français ou étrangers, des laboratoires publics ou privés. 


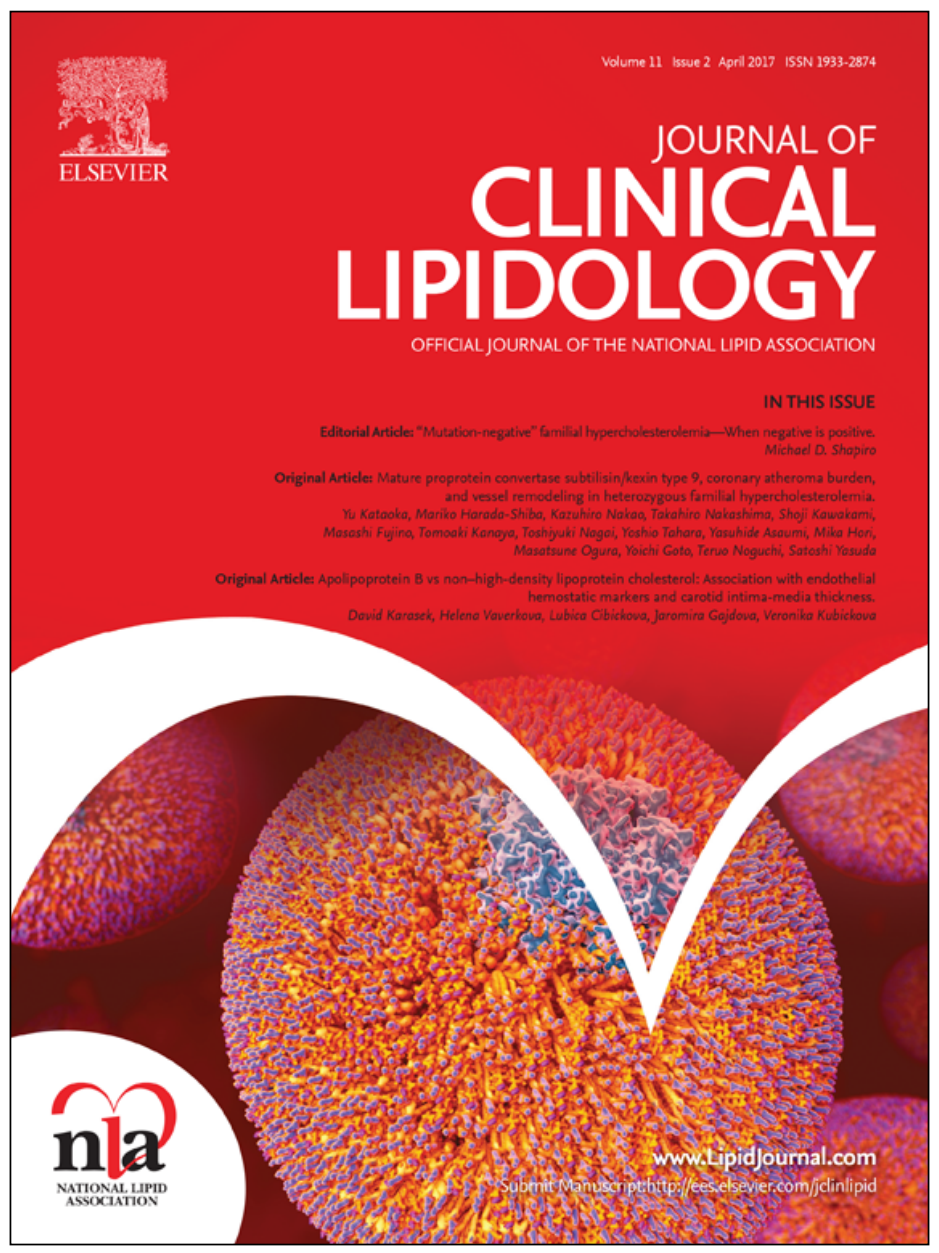

This article appeared in a journal published by Elsevier. The attached copy is furnished to the author for internal non-commercial research and education use, including for instruction at the author's institution and sharing with colleagues.

Other uses, including reproduction and distribution, or selling or licensing copies, or posting to personal, institutional or third party websites are prohibited.

In most cases authors are permitted to post their version of the article (e.g. in Word or Tex form) to their personal website or institutional repository. Authors requiring further information regarding Elsevier's archiving and manuscript policies are encouraged to visit:

http://www.elsevier.com/authorsrights 


\title{
Impact of bariatric surgery on apolipoprotein C-III levels and lipoprotein distribution in obese human subjects
}

\author{
Marie Maraninchi, $\mathrm{PhD}^{1}$, Nadège Padilla, $\mathrm{PhD}^{1}$, Sophie Béliard, MD, PhD, \\ Bruno Berthet, MD, Juan-Patricio Nogueira, MD, PhD, Jeanine Dupont-Roussel, \\ Julien Mancini, MD, PhD, Audrey Bégu-Le Corroller, MD, Noémie Dubois, MD, \\ Rachel Grangeot, MD, Catherine Mattei, MD, Marion Monclar, MD, \\ Anastasia Calabrese, MD, Carole Guérin, MD, Charles Desmarchelier, PhD, \\ Alain Nicolay, PhD, Changting Xiao, PhD, Patrick Borel, PhD, Gary F. Lewis, MD, \\ René Valéro, MD, PhD*
}

Aix-Marseille Univ, INSERM, INRA, NORT, Marseille, France (Drs Maraninchi, Padilla, Béliard, Dupont-Roussel, Desmarchelier, Nicolay, Borel, and Valéro); Department of Nutrition, Metabolic Diseases, Endocrinology, CHU La Conception, APHM, Marseille, France (Drs Béliard, Bégu-Le Corroller, Dubois, Grangeot, Mattei, Monclar, Calabrese, and Valéro); Department of General and Endocrine Surgery, La Conception Hospital, APHM, Marseille, France

(Drs Berthet and Guérin); Instituto Modelo de Gastroenterologia, Formosa, Argentina (Dr Nogueira); Facultad de Ciencias de la Salud, Universidad Nacional de Formosa, Formosa, Argentina (Dr Nogueira); Aix-Marseille Univ, INSERM, IRD, UMR912, SESSTIM, Marseille, France (Dr Mancini); Public Health Department (BIOSTIC), Timone Hospital, APHM, Marseille, France (Dr Mancini); Laboratory of Endocrine Biochemistry, La Conception Hospital, APHM, Marseille, France (Dr Nicolay); and Department of Medicine and Physiology, Banting and Best Diabetes Centre, University of Toronto, Ontario, Canada (Drs Xiao and Lewis)

KEYWORDS:

Apolipoprotein C-III;

Bariatric surgery;

Cardiovascular disease;

Dyslipidemia;

HDL;

Insulin resistance;

Lipoprotein metabolism;

Obesity;

Triglyceride-rich

lipoprotein
BACKGROUND: Elevated apolipoprotein C-III (apoC-III) has been postulated to contribute to the atherogenic dyslipidemia seen in obesity and insulin-resistant states, mainly by impairing plasma triglyceride-rich lipoprotein (TRL) metabolism. Bariatric surgery is associated with improvements of several obesity-associated metabolic abnormalities, including a reduction in plasma triglycerides (TGs) and an increase in plasma high-density lipoprotein cholesterol (HDL-C).

OBJECTIVES: We investigated the specific effect of bariatric surgery on apoC-III concentrations in plasma, non-HDL, and HDL fractions in relation to lipid profile parameters evolution.

METHODS: A total of 132 obese subjects undergoing bariatric surgery, gastric bypass $(n=61)$ or sleeve gastrectomy $(n=71)$, were studied 1 month before surgery and 6 and 12 months after surgery.

RESULTS: Plasma apoC-III, non-HDL-apoC-III, and HDL-apoC-III concentrations were markedly reduced after surgery and strongly associated with reduction in plasma TG. This decrease was

\footnotetext{
${ }^{1}$ These authors contributed equally to this work.

* Corresponding author. Service de Nutrition, Maladies métaboliques et Endocrinologie, Centre hospitalo-Universitaire de La Conception, 147 Boulevard Baille, 13005 Marseille, France.
} 
accompanied by a redistribution of apoC-III from TRL to HDL fractions. In multivariate analysis, plasma apoC-III was the strongest predictor of TG reduction after surgery, and the increase of HDL-C was positively associated with plasma adiponectin and negatively with body mass index.

CONCLUSION: Marked reduction of apoC-III and changes in its distribution between TRL and HDL consistent with a better lipid profile are achieved in obese patients after bariatric surgery. These apoCIII beneficial modifications may have implications in dyslipidemia improvement and contribute to cardiovascular risk reduction after surgery.

\section{Introduction}

The global epidemic of obesity represents a major public health threat. ${ }^{1}$ The relationship between the severity of obesity and increased risk of mortality and morbidity has been demonstrated in several studies. ${ }^{2,3}$ Cardiovascular disease is the dominant cause of mortality and morbidity in obesity. ${ }^{4}$ Dyslipidemia is often present in obesity and represents a major cardiovascular risk factor. This typical dyslipidemia of obese, insulin-resistant individuals is characterized by a quartet of abnormalities: hypertriglyceridemia, reduction in high-density lipoprotein cholesterol (HDL-C), increase of small and dense low-density lipoprotein (LDL) and postprandial hyperlipidemia. ${ }^{5}$ The pathophysiology of this dyslipidemia is widely explained by the blood accumulation of triglyceride-rich lipoproteins (TRL) from liver (very-low-density lipoprotein [VLDL]) and intestine (chylomicrons) origin. This accumulation has been attributed to the overproduction of both $\mathrm{VLDL}^{6}$ and chylomicrons ${ }^{7}$ and to a defective TRL removal process because of a number of associated mechanisms: reduction of lipoprotein lipase (LPL) activity, ${ }^{8}$ changes in the apolipoprotein composition of $\mathrm{TRL}^{9}$ impairing particle clearance, and defect in the hepatic uptake of TRL and their remnants. ${ }^{8}$

Apolipoprotein C-III (apoC-III) is synthesized by the liver and to a lesser extent by the intestine. ${ }^{10}$ In healthy individuals, plasma apoC-III is mainly present in TRL (VLDL and chylomicrons) and HDL and is redistributed from HDL to TRL in the postprandial state. ${ }^{11}$ Indeed, rapid exchanges occur between these particles, although nonexchangeable pools of TRL-apoC-III and HDL-apoC-III have been described. ${ }^{12}$ In hypertriglyceridemic subjects, apoC-III levels proportion bound to TRL are increased in the fasting state. ${ }^{13}$ Plasma apoC-III concentration is strongly correlated with plasma triglyceride (TG) concentration ${ }^{14,15}$ and is increased in insulin-resistant states (overweight or obesity ${ }^{15}$ and type II diabetes ${ }^{16,17}$ ). Elevated apoC-III has been postulated to contribute to the atherogenic dyslipidemia by the impairment of TRL and HDL metabolism including increased VLDL production and secretion, ${ }^{18}$ disturbance of TRL clearance by inhibiting LPL ${ }^{19}$ or hepatic lipase, ${ }^{20}$ and interfering with TRL and their remnant binding to hepatic lipoprotein receptors. ${ }^{21,22}$ Beyond the effects of apoC-III on TRL and HDL metabolism, this apolipoprotein has also been shown to promote inflammation and endothelial cell dysfunction, potentially contributing to atherosclerosis and cardiovascular disease. ${ }^{23,24}$ In several clinical studies, elevated apoC-III in HDL and non-HDL fractions was a significant predictor of coronary events and progression of coronary artery disease. ${ }^{25-28}$ More recently, genetic variants resulting in a loss of function and reduced apoC-III concentrations were associated with a reduction in the risk of coronary heart disease. ${ }^{29,30}$

Considering the increased mortality in obesity and the relative long-term ineffectiveness of conventional weightreducing treatments, bariatric surgery is now an accepted therapy worldwide for classes II and III of obesity. Two main procedures are performed: gastric bypass (GBP) and sleeve gastrectomy (SG). In long-term studies, bariatric surgery has been associated with a reduction of $29 \%$ in overall mortality compared with obese controls treated with conventional strategies. An important part of this decrease is due to the reduction of deaths from myocardial infarction in the surgery group. ${ }^{31}$ Reduction in several cardiovascular risk factors (hypertriglyceridemia, low HDL-C, diabetes, and hypertension) at 2 and 10 years follow-up could contribute to the improvement in the cardiovascular outcome. ${ }^{32}$ We have recently demonstrated a reduction in TRL production and an increase in particle clearance of obese subjects after bariatric surgery. ${ }^{33}$ However, the drastic improvement of dyslipidemia after bariatric surgery is not fully explained and to date, no study has been conducted to specifically investigate the effect of bariatric surgery on apoC-III.

In the present study, we investigated the effect of GBP and SG on plasma apoC-III concentration, its distribution in the lipoprotein fractions, and its relation to plasma lipid profile. We hypothesized that the improvement of lipid parameters including plasma TG reduction and HDL-C increase after bariatric surgery could be associated with a reduction of plasma apoC-III concentration and a favorable change in apoC-III distribution between TRL and HDL fractions.

\section{Materials and methods}

\section{Subjects}

A total of 132 obese patients referred to our Nutrition Department with an indication for bariatric surgery were recruited for this study. All participants were examined 
and followed by a multidisciplinary and integrated medical team consisting of an endocrinologist, a bariatric surgeon, a psychiatrist, and a dietician for at least 6 months before surgery. All the subjects met the indication criteria for bariatric surgery. ${ }^{34}$ The choice of the surgical procedure was not randomized but made by the patient and the multidisciplinary team, after a full explanation of the risks and possible benefits of each procedure. Bariatric surgery was performed by a single surgeon in the General and Endocrine Surgery Department. Sixty-one patients undergoing GBP and 71 patients undergoing SG were consecutively included. The clinical evaluation and laboratory tests were conducted at our Nutrition Department. The subjects were examined and followed by the multidisciplinary team before surgery and at least at 1, 3, 6, 9, and 12 months postsurgery with laboratory tests 1 month before and 6 and 12 months after surgery. Patients with type II diabetes met the diagnostic criteria for diabetes. ${ }^{35}$ The presurgery antidiabetic and hypolipidemic treatments of the patients are presented in Supplementary Table 1. This study was conducted in accordance with the Declaration of Helsinki, approved by the Research Ethics Board of Aix-Marseille University, and all subjects gave written informed consent.

\section{Study design}

Weight, fasting biochemical parameters, body composition, and energy intake (the diet of each subject was assessed by a dietician using a self-administered food diary completed during 3 days) were measured 1 month before surgery (M0) and at 6 months (M6) and 12 months (M12) after surgery. Our study was not powered or designed to compare the effectiveness of the 2 surgical procedures, one against the other.

\section{Laboratory methods}

Blood samples were collected after an overnight fast. Plasma was immediately separated by centrifugation at $2000 \mathrm{~g}$ for 15 minutes at $4^{\circ} \mathrm{C}$. Plasma TG, total cholesterol, HDL-C, and LDL-C were measured using an enzymatic colorimetric kit (cobas 6000 c 501 analyzer; Roche Diagnostics, Mannheim, Germany). Plasma glucose was assayed using the hexokinase oxidase method (cobas 6000 c 501 analyzer). Plasma insulin concentrations were determined using electrochemiluminescence method (cobas 6000 e 601 analyzer). Insulin resistance was estimated using the homeostasis model assessment as homeostasis model assessment-insulin resistance (HOMAIR) $=$ fasting insulin $(\mathrm{mUI} / \mathrm{L}) \times$ fasting glucose $(\mathrm{mmol} /$ L)/22.5. ${ }^{36}$ HOMA-IR was not calculated for those patients with diabetes to avoid the miscalculation of HOMA-IR due to the antidiabetic drugs taken by the patients. Total apoB and apoA-I plasma concentrations were determined by immunonephelometry assay (Roche Diagnostics) using a BN ProSpec analyzer (Siemens Healthineers, Erlangen,
Germany) and total plasma apoC-III and apoC-II levels by immunoturbidimetric assay (Kamiya Biomedical Company, Seattle, WA) using a cobas 6000 c 501 analyzer. HDL-apoC-III and HDL-apoC-II levels were measured in the supernatant after precipitation of TRL with phosphotungstic acid and magnesium chloride (bioMerieux, Marcy-l'Etoile, France). Non-HDL-apoC-III and nonHDL-apoC-II concentrations were calculated by subtracting HDL-apoC-III and HDL-apoC-II values from total plasma apoC-III and C-II measured levels. Specific enzyme-linked immunosorbent assay kit was used to measure serum levels of adiponectin (Quantikine Human Adiponectin; R\&D Systems, Minneapolis, MN). Body composition was assessed using dual-energy x-ray absorptiometry method (Lunar iDXA, GE Healthcare, Chalfont, St Giles, UK).

\section{Statistical analysis}

All statistical analyses were performed using IBM SPSS Statistics 20.0 (IBM Inc, NY) and managed by a statistician. Results are expressed as mean \pm standard deviation. Student $t$-test was used to compare GBP and SG surgical groups at M0 and at M6 and M12 after surgery. Paired $t$-test was used to compare the evolution of variables measured at different time points ( $\Delta \mathrm{M} 6-\mathrm{M} 0$, $\Delta \mathrm{M} 12-\mathrm{M} 0$, and $\Delta \mathrm{M} 12-\mathrm{M} 6)$. Pearson correlation coefficient was used to study the association between the different continuous variables. Backward stepwise linear regression models were used to study the independent predictors of $\Delta \mathrm{M} 12-\mathrm{M} 0 \mathrm{TG}$. Full model 1 was computed among total obese subjects cohort and included $\Delta \mathrm{M} 12-$ M0 of total apoC-II, non-HDL-apoC-II, total apoC-III, non-HDL-apoC-III, body mass index (BMI), apoB, apoA-I, fasting glucose. Full model 2 was computed among nondiabetic subjects and included the same variables as in the model 1 plus $\Delta$ M12-M0 HOMA-IR. All tests were 2 sided, and $P<.05$ was considered statistically significant.

\section{Results}

\section{Presurgery baseline demographic characteristics, fasting biochemical parameters, body composition, and energy intake of obese subjects}

At baseline, the GBP group was older $(P<.05)$ and more obese $(P<.05)$ compared with the SG group. There were more patients with diabetes and the fasting plasma glucose was higher in the GBP compared with the SG group $(P<.05$ for all $)$. We found no significant differences in sex ratio, energy intake, fat mass, lipid, apolipoprotein, and hormonal profiles between GBP and SG groups (Table 1). 
Table 1 Mean baseline demographic characteristics, fasting biochemical parameters, body composition, and energy intake in the GBP and SG groups of obese subjects

\begin{tabular}{|c|c|c|}
\hline Characteristics & $\mathrm{GBP}(n=61)$ & $\mathrm{SG}(n=71)$ \\
\hline Age $(y)$ & $46.2 \pm 9.6$ & $42.3 \pm 11.5^{a}$ \\
\hline $\begin{array}{r}\text { Sex ratio (F/M } \\
[\% \text { women }])\end{array}$ & $43 / 18(70.5)$ & $57 / 14(80.3)$ \\
\hline Weight (kg) & $124.6 \pm 21.6$ & $115.7 \pm 16.5^{b}$ \\
\hline BMI $\left(\mathrm{kg} / \mathrm{m}^{2}\right)$ & $44.9 \pm 6.4$ & $42.4 \pm 5.3^{a}$ \\
\hline Type II diabetics, $n$ & 24 & $15^{a}$ \\
\hline $\begin{array}{l}\text { Fasting glucose } \\
\qquad(\mathrm{mmol} / \mathrm{L})\end{array}$ & $6.8 \pm 3.2$ & $5.8 \pm 1.7^{a}$ \\
\hline $\begin{array}{l}\text { HOMA-IR (nondiabetic } \\
\text { cohort) }\end{array}$ & $6.09 \pm 4.44$ & $5.06 \pm 3.21$ \\
\hline Adiponectin $(\mu \mathrm{g} / \mathrm{mL})$ & $5.88 \pm 3.69$ & $6.56 \pm 3.47$ \\
\hline $\mathrm{TG}(\mathrm{mmol} / \mathrm{L})$ & $1.53 \pm 0.98$ & $1.60 \pm 0.95$ \\
\hline $\mathrm{TC}(\mathrm{mmol} / \mathrm{L})$ & $4.77 \pm 0.83$ & $4.82 \pm 0.83$ \\
\hline HDL-C (mmol/L) & $1.08 \pm 0.34$ & $1.11 \pm 0.34$ \\
\hline LDL-C (mmol/L) & $3.17 \pm 0.75$ & $3.12 \pm 0.65$ \\
\hline ApoA-I (g/L) & $1.45 \pm 0.22$ & $1.49 \pm 0.22$ \\
\hline$A p o B(g / L)$ & $0.95 \pm 0.20$ & $0.96 \pm 0.18$ \\
\hline ApoC-II (mg/L) & $43.85 \pm 14.48$ & $41.21 \pm 18.64$ \\
\hline ApoC-III (mg/L) & $116.26 \pm 42.70$ & $121.50 \pm 58.21$ \\
\hline Energy intake $(\mathrm{kJ} / \mathrm{d})$ & $8853 \pm 3257$ & $9239 \pm 3403$ \\
\hline Fat mass $(\%)$ & $50.9 \pm 5.1$ & $50.4 \pm 4.9$ \\
\hline
\end{tabular}

Apo, apolipoprotein; BMI, body mass index; GBP, gastric bypass; HDL-C, high-density lipoprotein-cholesterol; HOMA-IR, homeostasis model assessment-insulin resistance; LDL-C, low-density lipoproteincholesterol; SG, sleeve gastrectomy; TC, total cholesterol; TG, triglycerides.

Data are means \pm standard deviation. Mean data were compared in presurgery (M0) between GBP and SG groups $\left({ }^{a} P<.05 ;{ }^{b} P<.01\right)$.

\section{Effects of bariatric surgery on BMI, insulin resistance, adiponectin, body composition, and energy intake}

When we compared presurgery to postsurgery (1 month before vs 6 or 12 months after surgery: $\Delta \mathrm{M} 6-\mathrm{M} 0$ or $\Delta \mathrm{M} 12-$ M0) parameters, we found a significant and similar reduction in weight, BMI, plasma fasting glucose, HOMA-IR, energy intake, and fat mass and a significant and similar increase in adiponectin after surgery in both GBP and SG groups $(P<.001$ for all these parameters except $\Delta$ M6-M0 for HOMA-IR in GBP, $P<.01$; Table 2).

\section{Effects of bariatric surgery on plasma lipids}

In $\Delta \mathrm{M} 6-\mathrm{M} 0$ and $\Delta \mathrm{M} 12-\mathrm{M} 0$ analyses of plasma lipid concentrations, we found a significant and similar reduction in plasma TG after surgery in both GBP $(P<.01$ at M6 and $P<.001$ at M12) and SG groups $(P<.001$ at M6 and M12) and a significant and similar increase in HDL-C at M12 in both GBP $(P<.01)$ and SG $(P<.001)$ groups. At M6, HDL-C increased significantly only in the SG group $(P<.05$; Table 3$)$.
We found a significant reduction in plasma TC and LDL-C only in the GBP group at M6 and M12 $(P<.01$ for TC and $P<.001$ for LDL-C; Table 3).

\section{Effects of bariatric surgery on apolipoproteins and distribution of apoC-III and apoC-II in HDL and non-HDL fractions}

After surgery, there was a significant reduction in plasma apoB in the GBP group at M6 $(P<.01)$ and M12 $(P<.001)$ and in the SG group only at M12 $(P<.05)$ and the reduction in apoB was significantly greater in the GBP compared with the SG group at M6 and M12 $(P<.05$ for both). ApoA-I decreased significantly in the GBP group at M6 $(P<.01)$ but with no change at M12 compared with presurgery and increased significantly in the SG group at M12 only $(P<.01)$. Between M6 and M12, apoA-I increased significantly in both groups $(P<.001$; Table 3$)$.

In $\Delta$ M6-M0 and $\Delta$ M12-M0 analyses, we found a significant and similar reduction in total apoC-III, total apoC-II, non-HDL-apoC-III, HDL-apoC-III, and apoC-III/ apoC-II ratio after surgery in both GBP and SG groups. In $\triangle \mathrm{M} 12-\mathrm{M} 6$, there was a significant increase in HDL-apoCIII in $\operatorname{GBP}(P<.05)$ and reduction in non-HDL-apoC-III in SG $(P<.01)$. There was a significant reduction in HDLapoC-II in $\Delta \mathrm{M} 12-\mathrm{M} 0$ in both groups $(P<.01)$, in $\Delta \mathrm{M} 6$ M0 in the SG $(P<.01)$ and in $\Delta$ M12-M6 in the GBP group $(P<.05)$ and a significant reduction in non HDL-apoC-II in $\triangle \mathrm{M} 12-\mathrm{M} 0$ in the $\mathrm{SG}$ group $(P<.01)$. There were no significant reductions in plasma apoC-III, apoC-II, or apoCIII/apoC-II ratio in $\Delta$ M12-M6 in either group (Tables 3 and 4).

In statistical analyses of the total group of obese subjects undergoing either bariatric surgical procedure, we found a significant reduction in plasma apoC-III and apoC-II in $\Delta$ M6-M0 $(-28 \%$ and $-9 \%$ respectively; $P<.001$ and $P<.01$ respectively), in $\Delta$ M12-M0 $(-31 \%$ and $-18 \%$ respectively; $P<.001$ for both) but a significant reduction only for apoC-II in $\Delta$ M12-M6 $(P<.05$; Fig. 1 , Table 5$)$.

When we compared the concentrations of apoC-III and apoC-II in non-HDL and HDL fractions for the total group of obese subjects, we found a significant reduction of apoCIII in non-HDL and HDL fractions at M6 and M12 $(P<.001$ for all). In $\Delta$ M12-M6-specific analyses, we found a significant reduction in non-HDL-apoC-III $(P<.05)$ and a significant increase in HDL-apoC-III $(P<.01)$. For apoC-II, we found a significant reduction in non-HDL and HDL fractions at M6 $(P<.05$ for both $)$ and at M12 $(P<.01$ for both) but no change in $\Delta$ M12-M6 (Fig. 2A and $\mathrm{B}$, Table 5).

When we considered the distribution of apoC-III between non-HDL and HDL fractions, we found no change at M6 of apoC-III distribution between fractions (55\% at M0 vs $55 \%$ at M6 for non-HDL-apoC-III fraction and $45 \%$ at M0 vs $45 \%$ at M6 for HDL-apoC-III fraction). In $\Delta \mathrm{M} 12-$ M6 analysis, we found a significant change in the 
Table 2 Mean presurgery (M0) and postsurgery evolution at 6 months (M6) and at 12 months (M12) of weight, BMI, insulin resistance, adiponectin, energy expenditure, and energy intake in the GBP and SG groups of obese subjects

\begin{tabular}{|c|c|c|c|c|c|c|}
\hline \multirow[b]{2}{*}{ Parameters } & \multicolumn{3}{|l|}{ GBP } & \multicolumn{3}{|l|}{ SG } \\
\hline & MO & $\Delta \mathrm{M6}-\mathrm{M0}$ & $\Delta \mathrm{M} 12-\mathrm{M0}$ & MO & $\Delta \mathrm{M6}$-M0 & $\Delta \mathrm{M} 12-\mathrm{M} 0$ \\
\hline Weight (kg) & $124.6 \pm 21.6$ & $-28.0 \pm 10.3^{b}$ & $-35.6 \pm 14.5^{b}$ & $115.7 \pm 16.5^{d}$ & $-28.2 \pm 9.1^{b}$ & $-32.24 \pm 12.0^{b}$ \\
\hline $\operatorname{BMI}\left(\mathrm{kg} / \mathrm{m}^{2}\right)$ & $44.9 \pm 6.4$ & $-10.0 \pm 3.3^{b}$ & $-12.6 \pm 4.8^{b}$ & $42.4 \pm 5.3^{c}$ & $-10.3 \pm 3.2^{b}$ & $-11.8 \pm 4.4^{b}$ \\
\hline Fasting glucose (mmol/L) & $6.8 \pm 3.2$ & $-1.3 \pm 2.6^{b}$ & $-1.3 \pm 2.3^{b}$ & $5.8 \pm 1.7^{c}$ & $-0.8 \pm 1.6^{b}$ & $-0.9 \pm 1.4^{b}$ \\
\hline $\begin{array}{l}\text { HOMA-IR (nondiabetic } \\
\text { cohort) }\end{array}$ & $6.09 \pm 4.44$ & $-3.85 \pm 4.72^{a}$ & $-3.39 \pm 3.19^{b}$ & $5.06 \pm 3.21$ & $-3.15 \pm 2.43^{b}$ & $-3.53 \pm 2.70^{b}$ \\
\hline Adiponectin $(\mu \mathrm{g} / \mathrm{mL})$ & $5.88 \pm 3.69$ & $2.41 \pm 2.94^{b}$ & $4.25 \pm 4.59^{b}$ & $6.56 \pm 3.47$ & $2.17 \pm 2.85^{b}$ & $4.39 \pm 4.16^{b}$ \\
\hline Energy intake $(\mathrm{kJ} / \mathrm{d})$ & $8853 \pm 3257$ & $-4420 \pm 3361^{b}$ & $-3914 \pm 3621^{b}$ & $9239 \pm 3403$ & $-4642 \pm 3169^{b}$ & $-4333 \pm 3470^{b}$ \\
\hline Fat mass $(\%)$ & $50.9 \pm 5.1$ & $-7.81 \pm 3.47^{b}$ & $-12.28 \pm 5.92^{b}$ & $50.4 \pm 4.9$ & $-8.64 \pm 4.05^{b}$ & $-12.21 \pm 5.26^{b}$ \\
\hline
\end{tabular}

BMI, body mass index; GBP, gastric bypass; HDL, high-density lipoprotein; HOMA-IR, homeostasis model assessment-insulin resistance; SG, sleeve gastrectomy.

Data are means \pm standard deviation. Mean data were compared between presurgery (M0) and postsurgery (M6 or M12) in each group $\left({ }^{a} P<.01\right.$; $\left.{ }^{b} P<.001\right)$ and between GBP and SG groups $\left({ }^{c} P<.05 ;{ }^{d} P<.01\right)$.

distribution of apoC-III between fractions $(55 \%$ at $\mathrm{M} 0$ vs $50 \%$ at M12 for non-HDL-apoC-III fraction and $45 \%$ at M0 vs $50 \%$ at M12 for HDL-apoC-III fraction; $P<.01$ for both). For apoC-II, we found no change in non-HDL and HDL distribution between pre- and postsurgery (Fig. 2A and $\mathrm{B}$, Table 5).

\section{Presurgery (M0), postsurgery (M12) and delta post- vs pre-surgery ( $\triangle M 12-M 0)$ correlations between lipids, apolipoproteins, biochemical, body composition, and energy intake parameters in the total cohort of obese subjects}

M0 and M12 univariate analyses are presented in Supplementary Tables 2 and 3 respectively.

In $\Delta \mathrm{M} 12-\mathrm{M} 0$ univariate analyses, we found strong positive associations between $\Delta \mathrm{TG}$ and $\Delta$ apoC-III, $\Delta$ nonHDL-apoC-III, $\Delta$ HDL-apoC-III, $\Delta$ apoC-II, $\Delta$ non HDLapoC-II, and $\Delta$ HDL-apoC-II $(r>0.45$ and $P<.001$ for all). There was a significant positive association between $\Delta$ HDL-C and $\Delta$ adiponectin $(r=0.304$ and $P<.01)$ and a significant negative association between $\triangle$ HDL-C and $\Delta$ BMI $(r=-0.223$ and $P<.05$; Table 6$)$.

In $\Delta \mathrm{M} 12-\mathrm{M} 0$ multivariate regression model analyses, $\Delta$ apoC-III in model 1 (total obese cohort) explained $56 \%$ of TG variation (full model adjusted $R^{2}=0.582$; final model adjusted $\left.R^{2}=0.556\right)$ and $\Delta$ apoC-III and $\Delta$ apoA-I in model 2 (nondiabetic cohort) explained $71 \%$ of TG variation (full model adjusted $R^{2}=0.689$; final model adjusted $R^{2}=0.713$; Table 7).

\section{Discussion}

In the present study, we report the effects of 2 types of bariatric surgery (GBP and SG) on apoC-III that include a marked reduction in plasma apoC-III, non-HDL-apoC-III, and HDL-apoC-III concentrations and a redistribution of apoC-III from non-HDL to HDL fraction, consistent with an improved lipid profile.

Here, the marked and similar reductions in BMI, fat mass, energy intake and the improvement in insulin sensitivity after bariatric surgery in both GBP and SG groups were accompanied by a significant reduction in fasting plasma TG and an increase in HDL-C. These findings confirm the results of several studies and metaanalyses in short-term (6-12 months) and long-term ( $\geq 12$ months) follow-up after bariatric surgery.

We found a specific decrease in plasma TC and LDL-C after GBP but not after SG. These findings are in keeping with other studies showing that mixed malabsorptive and restrictive surgery (GBP) is more effective than restrictive surgery (SG) in reducing cholesterol levels ${ }^{37,38}$ and more specifically that TC and LDL-C are significantly reduced 12 months after GBP but not after SG. ${ }^{39}$ In malabsorptive surgery, it has been shown that intestinal cholesterol absorption decreases leading to decreased plasma TC and LDL-C concentrations, accompanied by enhanced hepatic cholesterol synthesis and catabolism. ${ }^{40}$ In the present study, the greater reduction in total apoB in GBP compared with SG could be explained by a specific reduction of LDL particle numbers in GBP.

Our findings are in keeping with the recently published scientific statement on lipids and bariatric procedures. ${ }^{41,42}$

In a recent lipoprotein kinetic study, we have shown improved TRL metabolism after bariatric surgery (GBP and SG) in nondiabetic, obese, insulin-resistant humans with normolipidemia or mild dyslipidemia. This improvement was manifested by decreased production of VLDL and chylomicrons and increased clearance of VLDL. ${ }^{33}$ VLDL and chylomicrons are overproduced in insulin-resistant subjects compared with healthy controls, ${ }^{6,7,43-46}$ and this overproduction seems to result, in part, from decreased sensitivity to the acute inhibitory effect of insulin on 


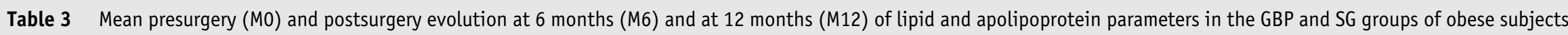

\begin{tabular}{|c|c|c|c|c|c|c|c|c|}
\hline \multirow[b]{2}{*}{ Parameters } & \multicolumn{4}{|l|}{ GBP } & \multicolumn{4}{|l|}{ SG } \\
\hline & MO & $\Delta \mathrm{M6}$ - M0 & $\Delta \mathrm{M} 12-\mathrm{M0}$ & $\Delta M 12-M 6$ & MO & $\Delta \mathrm{M6}$-M0 & $\Delta \mathrm{M} 12-\mathrm{M} 0$ & $\Delta \mathrm{M} 12-\mathrm{M} 6$ \\
\hline $\mathrm{TG}(\mathrm{mmol} / \mathrm{L})$ & $1.53 \pm 0.98$ & $-0.42 \pm 0.93^{b}$ & $-0.44 \pm 0.66^{c}$ & $-0.13 \pm 0.49$ & $1.60 \pm 0.95$ & $-0.50 \pm 0.75^{c}$ & $-0.64 \pm 0.73^{c}$ & $-0.08 \pm 0.36$ \\
\hline $\mathrm{TC}(\mathrm{mmol} / \mathrm{L})$ & $4.77 \pm 0.83$ & $-0.41 \pm 0.83^{b}$ & $-0.44 \pm 1.01^{b}$ & $0.08 \pm 0.83$ & $4.82 \pm 0.83$ & $0.05 \pm 0.83^{e}$ & $0.08 \pm 0.90^{e}$ & $0.03 \pm 0.65$ \\
\hline $\mathrm{HDL}-\mathrm{C}(\mathrm{mmol} / \mathrm{L})$ & $1.08 \pm 0.34$ & $0.03 \pm 0.23$ & $0.15 \pm 0.31^{b}$ & $0.21 \pm 0.21^{c}$ & $1.11 \pm 0.34$ & $0.10 \pm 0.31^{a}$ & $0.21 \pm 0.34^{c}$ & $0.15 \pm 0.21^{c}$ \\
\hline LDL-C (mmol/L) & $3.17 \pm 0.75$ & $-0.39 \pm 0.72^{c}$ & $-0.57 \pm 0.88^{c}$ & $-0.13 \pm 0.72$ & $3.12 \pm 0.65$ & $0.03 \pm 0.67^{e}$ & $0.03 \pm 0.83^{e}$ & $-0.03 \pm 0.62$ \\
\hline ApoA-I $(\mathrm{g} / \mathrm{L})$ & $1.45 \pm 0.22$ & $-0.08 \pm 0.16^{b}$ & $0.04 \pm 0.18$ & $0.15 \pm 0.15^{c}$ & $1.49 \pm 0.22$ & $-0.01 \pm 0.17^{d}$ & $0.11 \pm 0.22^{b}$ & $0.12 \pm 0.19^{c}$ \\
\hline ApoB (g/L) & $0.95 \pm 0.20$ & $-0.10 \pm 0.21^{b}$ & $-0.15 \pm 0.20^{c}$ & $-0.02 \pm 0.17$ & $0.96 \pm 0.18$ & $-0.02 \pm 0.15^{d}$ & $-0.07 \pm 0.18^{a, d}$ & $-0.03 \pm 0.13$ \\
\hline ApoC-II (mg/L) & $43.85 \pm 14.48$ & $-3.78 \pm 12.36^{a}$ & $-7.82 \pm 12.78^{c}$ & $-2.63 \pm 10.29$ & $41.21 \pm 18.64$ & $-4.15 \pm 13.79^{a}$ & $-7.64 \pm 13.53^{c}$ & $-1.43 \pm 9.96$ \\
\hline ApoC-III (mg/L) & $116.26 \pm 42.70$ & $-34.42 \pm 33.89^{c}$ & $-32.84 \pm 33.00^{c}$ & $-1.08 \pm 27.82$ & $121.50 \pm 58.21$ & $-32.10 \pm 41.51^{c}$ & $-38.15 \pm 45.07^{c}$ & $-0.13 \pm 20.66$ \\
\hline ApoC-III/ApoC-II ratio & $2.72 \pm 0.84$ & $-0.62 \pm 0.74^{c}$ & $-0.38 \pm 0.74^{b}$ & $0.12 \pm 0.44$ & $3.08 \pm 0.91^{d}$ & $-0.66 \pm 0.84^{c}$ & $-0.49 \pm 0.91^{c}$ & $0.19 \pm 0.82$ \\
\hline
\end{tabular}

Apo, apolipoprotein; GBP, gastric bypass; HDL-C, high-density lipoprotein cholesterol; LDL-C, low-density lipoprotein cholesterol; SG, sleeve gastrectomy; TC, total cholesterol; TG, triglycerides.

Data are means \pm standard deviation. Mean data were compared between presurgery (M0) and postsurgery (M6 or M12) and between postsurgery (M6 and M12) in each group $\left({ }^{a} P<.05 ;{ }^{b} P<.01\right.$;

$\left.{ }^{c} P<.001\right)$ and between GBP and SG groups $\left({ }^{d} P<.05 ;{ }^{e} P<.01\right)$.

Table 4 Mean presurgery (M0) and postsurgery evolution at 6 months (M6) and at 12 months (M12) of apoC-II and apoC-III in HDL and non-HDL fractions in the GBP and SG groups of obese subjects

\begin{tabular}{|c|c|c|c|c|c|c|c|c|}
\hline \multirow[b]{2}{*}{ Parameters } & \multicolumn{4}{|l|}{ GBP } & \multicolumn{4}{|l|}{ SG } \\
\hline & MO & $\Delta$ M6-MO & $\Delta \mathrm{M} 12-\mathrm{M0}$ & $\Delta$ M12-M6 & MO & $\Delta$ M6-MO & $\Delta$ M12-M0 & $\Delta$ M12-M6 \\
\hline HDL-apoC-II (mg/L) & $27.13 \pm 8.89$ & $-1.05 \pm 8.48$ & $-4.90 \pm 8.75^{b}$ & $-2.26 \pm 6.46^{a}$ & $26.38 \pm 11.30$ & $-2.63 \pm 9.06^{b}$ & $-4.37 \pm 9.90^{b}$ & $\begin{array}{l}-0.49 \pm 7.96 \\
-120+827\end{array}$ \\
\hline $\begin{array}{l}\text { non HDL-apoC-II (mg/L) } \\
\text { HDL-apoC-III (mg/L) }\end{array}$ & $\begin{array}{l}15.60 \pm 8.93 \\
52.56 \pm 24.13\end{array}$ & $\begin{aligned}-1.43 & \pm 9.31 \\
-17.12 & \pm 19.14^{c}\end{aligned}$ & $\begin{aligned}-1.99 & \pm 8.73 \\
-12.27 & \pm 16.64^{c}\end{aligned}$ & $\begin{aligned}-1.13 & \pm 8.48 \\
3.79 & \pm 11.01^{a}\end{aligned}$ & $\begin{array}{l}15.93 \pm 8.88 \\
56.39 \pm 32.69\end{array}$ & $\begin{aligned}-2.18 & \pm 8.50 \\
-16.85 & \pm 25.09^{c}\end{aligned}$ & $\begin{aligned}-4.15 & \pm 8.28^{b} \\
-15.75 & \pm 27.80^{c}\end{aligned}$ & $\begin{aligned}-1.20 & \pm 8.27 \\
3.96 & \pm 13.92\end{aligned}$ \\
\hline non HDL-apoc-III (mg/L) & $64.64 \pm 25.39$ & $-18.21 \pm 24.15^{c}$ & $-20.30 \pm 19.82^{c}$ & $-4.23 \pm 22.95$ & $65.85 \pm 32.68$ & $-15.91 \pm 25.26^{c}$ & $-24.62 \pm 28.58^{c}$ & $-6.66 \pm 14.40^{b}$ \\
\hline
\end{tabular}

Apo, apolipoprotein; GBP, gastric bypass; HDL, high-density lipoprotein; NS, not significant; SG, sleeve gastrectomy.

Data are means \pm standard deviation. Mean data were compared between presurgery (M0) and postsurgery (M6 or M12) and between postsurgery (M6 and M12) in each group $\left({ }^{a} P<.05 ;{ }^{b} P<.01\right.$; $\left.{ }^{c} P<.001\right)$ and between GBP and SG groups (NS). 


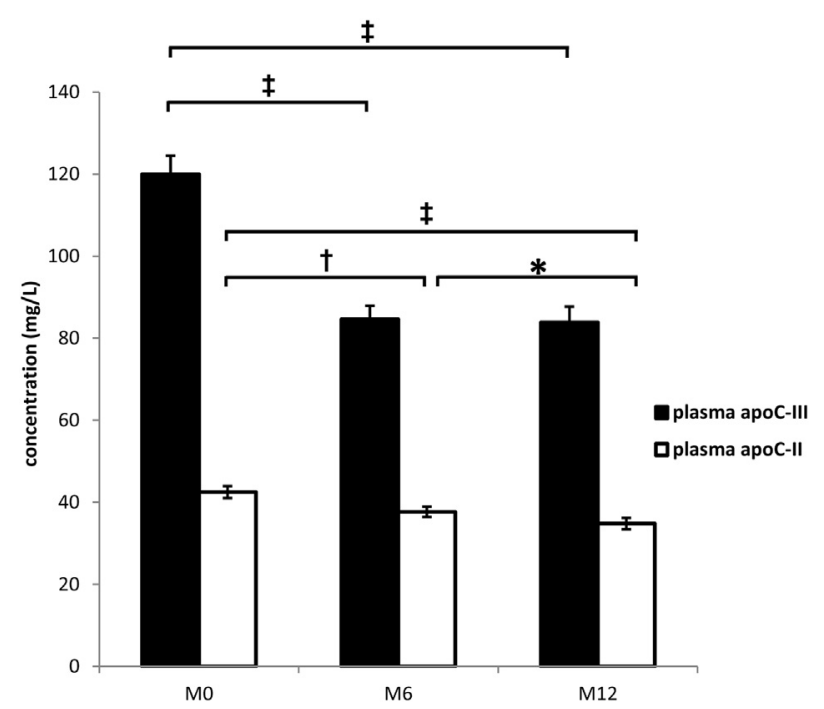

Figure 1 ApoC-III and apoC-II in presurgery (M0) and in postsurgery (at 6 months [M6] and at 12 months [M12]) in the total cohort of obese subjects. Data are means \pm standard error of the mean. Mean data were compared between presurgery (M0) and postsurgery (M6 and M12) and between M12 and M6 after surgery $\left({ }^{*} P<.05 ;{ }^{\dagger} P<.01 ;{ }^{\ddagger} P<.001\right)$. Apo, apolipoprotein.

VLDL and chylomicron secretion. ${ }^{5}$ Moreover, reduced activity of LPL has been shown in insulin-resistant subjects compared with control subjects in fasting and postprandial states. ${ }^{47,48}$ This reduction in lipolytic activity seems also to be related to insulin resistance, insulin being a potent activator of LPL. ${ }^{49}$ In the present study, the marked improvement in insulin sensitivity after bariatric surgery and its effects on TRL production and LPL activity could explain the decrease in plasma TG concentrations. Hypertriglyceridemia is a major factor contributing to HDL catabolism and to the increased formation of atherogenic small and dense LDL particles. ${ }^{49}$ The decrease in plasma TG could partly explain the increase in HDL-C after surgery. Our univariate analyses showed a significant negative association between TG and HDL-C at M0 and M12. Our multivariate regression model analysis confirmed the significant and negative association between the changes $(\Delta \mathrm{M} 12-\mathrm{M} 0)$ in plasma TG and apoA-I (model 2). We found a positive association between plasma TG and HOMA-IR and a negative association between HDL-C and HOMA-IR at M6 and M12 after surgery. Moreover, it has been shown in subjects with abdominal obesity that the fractional catabolic rate (FCR) of apoA-I is independently associated with both catabolism and production of $\mathrm{VLDL}_{1}-\mathrm{TG}^{50} \mathrm{We}$ also found a significant positive association between the increase in plasma adiponectin and the increase in HDL-C $(\Delta \mathrm{M} 12-\mathrm{M} 0)$. A significant negative correlation has already been reported between HDL-apoA-I catabolism and plasma adiponectin, independent of insulin resistance and plasma lipids, suggesting as in our study a direct effect of adiponectin on HDL metabolism. ${ }^{49}$

We found a marked, significant reduction of total plasma apoC-III and non-HDL-apoC-III concentrations after GBP and $\mathrm{SG}$ and strong positive associations between plasma apoC-III or non-HDL-apoC-III and plasma TG in M0, $\mathrm{M} 12$, and $\Delta \mathrm{M} 12-\mathrm{M} 0$ univariate analyses.

There are various explanations accounting for the relationship between the reduction in TRL and apoC-III after bariatric surgery. One possibility is that the reduction in TRL production and the increase in TRL catabolism previously shown after bariatric surgery, in the context of weight loss and a clear improvement in insulin sensitivity, ${ }^{33}$ may lead to a reduction of apoC-III, which is mainly bound to TRL. This explanation may also apply to the parallel significant reduction of total plasma apoC-II and non-HDLapoC-II after GBP and SG and the strong positive associations between plasma apoC-II or non-HDL-apoC-II and plasma TG in M0, M12, and $\Delta \mathrm{M} 12-\mathrm{M} 0$ analyses, despite the stimulating role of apoC-II on TRL catabolism. ApoC-III and apoC-II are bound to the same lipoproteins, mainly TRL and HDL, and we found a strong positive association between all the following parameters: plasma apoC-III, non-HDL-apoC-III, plasma apoC-II, non-HDLapoC-II levels in M0, M12, and $\Delta \mathrm{M} 12-\mathrm{M} 0$ analyses.

An alternative explanation is that the reduction in nonHDL-apoC-III after bariatric surgery could partly explain the reduction in plasma TG by the actions of apoC-III on TRL metabolism. First, apoC-III has been shown to

Table 5 Mean presurgery (MO) and postsurgery evolution at 6 months (M6) and at 12 months (M12) of apoC-II and apoC-III in plasma, HDL, and non-HDL fractions in the total cohort of obese subjects

\begin{tabular}{lccrr}
\hline Parameters & M0 & $\Delta$ M6-M0 & $\Delta$ M12-M0 & $\Delta$ M12-M6 \\
\hline ApoC-II (mg/L) & $42.50 \pm 16.43$ & $-3.74 \pm 13.09^{b}$ & $-7.71 \pm 12.92^{c}$ & $-2.52 \pm 9.88^{a}$ \\
HDL-apoC-II (mg/L) & $26.72 \pm 10.23$ & $-1.91 \pm 8.79^{a}$ & $-4.64 \pm 9.29^{b}$ & $-1.35 \pm 7.28$ \\
Non-HDL-apoC-II (mg/L) & $15.78 \pm 8.87$ & $-1.84 \pm 8.85^{a}$ & $-3.07 \pm 8.53^{b}$ & $-1.17 \pm 8.32$ \\
ApoC-III (mg/L) & $119.96 \pm 51.29$ & $-33.94 \pm 37.88^{c}$ & $-36.72 \pm 38.64^{c}$ & $-1.58 \pm 23.03$ \\
HDL-apoC-III (mg/L) & $54.66 \pm 29.08$ & $-16.97 \pm 22.46^{c}$ & $-14.12 \pm 23.21^{c}$ & $3.88 \pm 12.49^{b}$ \\
Non-HDL-apoC-III (mg/L) & $65.30 \pm 29.50$ & $-16.97 \pm 24.67^{c}$ & $-22.60 \pm 24.84^{c}$ & $-5.46 \pm 19.02^{a}$ \\
\hline
\end{tabular}

Apo, apolipoprotein; HDL, high-density lipoprotein.

Data are means \pm standard deviation. Mean data were compared between presurgery (M0) and postsurgery (M6 or M12) and between postsurgery (M6 and M12) in the total cohort of obese subjects $\left({ }^{a} P<.05 ;{ }^{b} P<.01{ }^{c} P<.001\right)$. 

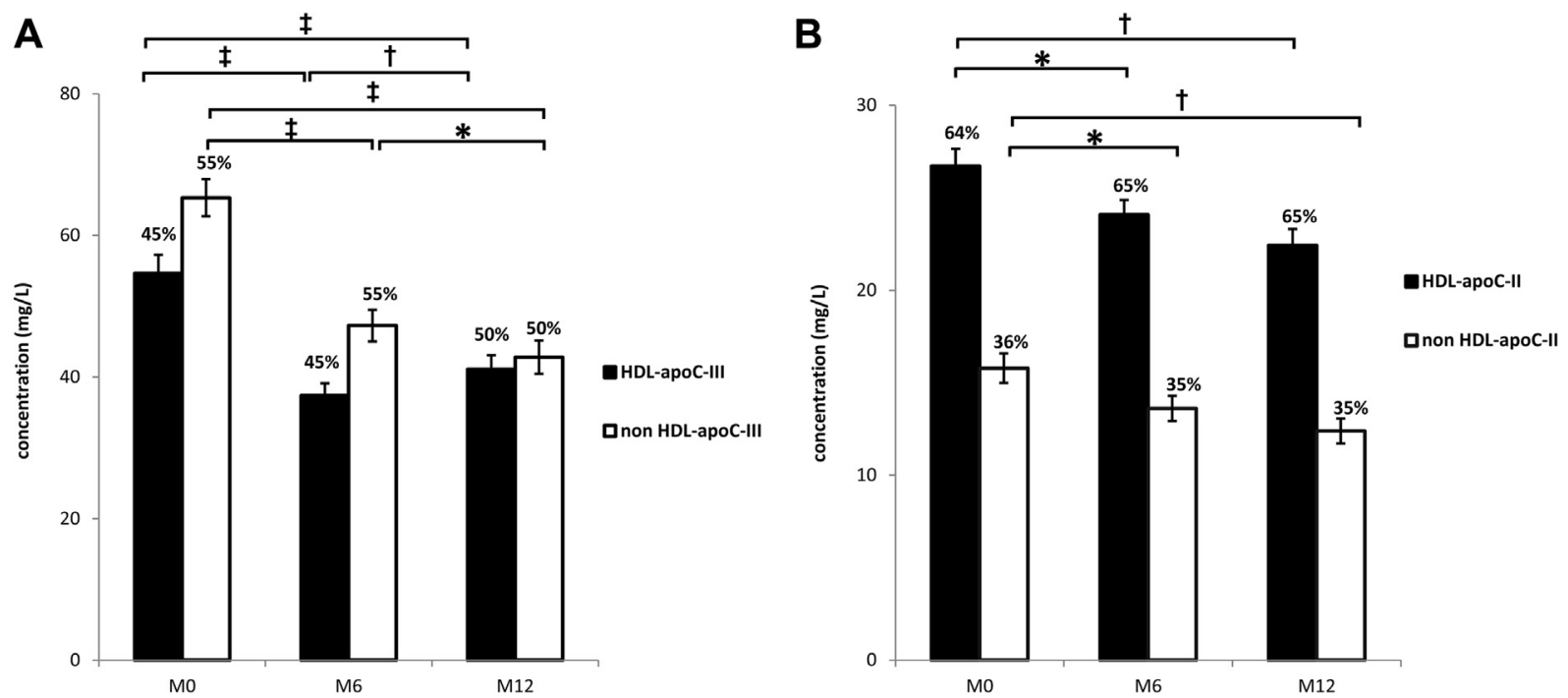

Figure 2 ApoC-III (A) and apoC-II (B) in HDL and non-HDL fractions in presurgery (M0) and in postsurgery (at 6 months [M6] and at 12 months [M12]) in the total cohort of obese subjects. Data are means \pm standard error of the mean. Mean data were compared between presurgery (M0) and postsurgery (M6 and M12) and between M12 and M6 after surgery $\left({ }^{*} P<.05 ;{ }^{\dagger} P<.01\right.$; $\left.{ }^{\ddagger} P<.001\right)$. Apo, apolipoprotein; HDL, high-density lipoprotein.

promote hepatic VLDL1 production. ${ }^{18}$ ApoC-III is mainly synthesized in the liver and its expression is suppressed by insulin ${ }^{51}$ and stimulated by glucose. ${ }^{52}$ Here, the significant decrease of fasting glucose and the improvement of insulin sensitivity after GBP and SG could have played a role in reducing hepatic apoC-III expression, with subsequent reduction in VLDL1 production. Second, it is well known that apoC-III is an inhibitor of LPL activity. ${ }^{19}$ Third, several studies have shown that apoC-III inhibits receptor-mediated uptake of TRL by the liver. ${ }^{21,22}$

Kinetic studies using tracer methodology have confirmed that VLDL-apoC-III is overproduced in overweight insulin-resistant subjects, ${ }^{15}$ in hypertriglyceridemic subjects compared with controls, ${ }^{53}$ and in centrally, obese men compared with controls. ${ }^{54}$ Increased plasma concentrations of apoC-III are associated with impaired VLDL1 clearance in obese insulin-resistant $\operatorname{men}^{55}$ and VLDLapoC-III clearance is reduced in centrally obese men compared with controls. ${ }^{54}$ Furthermore, plasma TG concentrations in abdominal obesity are determined by the kinetics of $\mathrm{VLDL}_{1}$ particles, their catabolism being mainly dependent on apoC-III concentration ${ }^{56}$ and apoC-III levels have been identified as significant determinants of the kinetics and plasma concentrations of TRLs. ${ }^{57}$ VLDLapoC-III concentration was also shown to be positively, independently, and significantly associated with HDLapoA-I clearance. ${ }^{54}$ We found a significant decrease of non HDL-apoC-III, which inhibits LPL, and of non-HDLapoC-II, which stimulates LPL. However, the reduction in non-HDL-apoC-III was clearly higher than that in non-HDL-apoC-II for both GBP and SG at M6 and M12, leading to a significant reduction in total plasma apoCIII/apoC-II ratio after surgery. For the total cohort, the decrease in non-HDL-apoC-III was also higher than that of non-HDL-apoC-II $(-26 \%$ vs $-12 \%$ at M6 and $-35 \%$ vs $-20 \%$ at M12). Our $\Delta \mathrm{M} 12-\mathrm{M} 0$ multivariate regression model analyses confirmed the strong and significant positive association between plasma TG and total plasma apoC-III (models 1 and 2), apoC-III being the strongest predictor of TG variation after surgery. From all these data, we suggest that the marked reduction in plasma apoC-III or more particularly non-HDL-apoC-III after bariatric surgery might have contributed to the improvement of TRL metabolism, that is, decreased production and increased clearance of TRL, leading to a reduction in plasma TG and an increase in HDL-C.

Both of the previously mentioned changes (ie, reductions in TRL and apoC-III) could occur concurrently, with one affecting the other. Reductions in TRL secondary to marked reductions in body weight, energy intake, and insulin resistance post-bariatric surgery reduce the concentration of apoC-III bound to the TRL fraction. Redistribution of apoC-III from TRL to HDL fractions after bariatric surgery may further contribute to this reduction in TRLassociated apoC-III. Reductions in TRL-bound apo-CIII in turn play an active role in contributing to further reductions in TRL concentrations. Definitive proof of a bidirectional causative relationship between TRL and apoC-III reductions awaits further mechanistic study.

Change occurring in the distribution of apoC-III between non-HDL and HDL fractions is another important finding of our study. Here, we confirmed the results of several studies showing that apoC-III levels associated with TRL in the fasted state are increased in hypertriglyceridemic subjects. ${ }^{13,58}$ After a parallel decrease in apoC-III in non-HDL and HDL fractions with no change in the distribution of apoC-III between non-HDL (55\%) and HDL (45\%) fractions at M6 after surgery, we found a divergent 


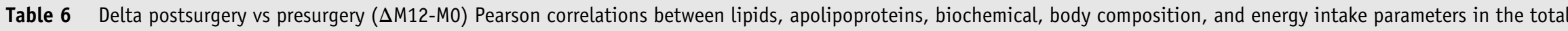
cohort of obese subjects

\begin{tabular}{|c|c|c|c|c|c|c|c|c|c|c|}
\hline Parameters & $\mathrm{TC}$ & TG & HDL-C & LDL-C & ApoC-II & HDL-apoC-II & Non-HDL-apoC-II & ApoC-III & HDL-apoC-III & Non-HDL-apoC-III \\
\hline \multicolumn{11}{|l|}{$\overline{\mathrm{TC}}$} \\
\hline TG & $0.360^{c}$ & & & & & & & & & \\
\hline HDL-C & $0.257^{a}$ & -0.072 & & & & & & & & \\
\hline LDL-C & $0.888^{c}$ & 0.144 & 0.049 & & & & & & & \\
\hline ApoC-II & $0.384^{c}$ & $0.618^{c}$ & 0.003 & $0.248^{a}$ & & & & & & \\
\hline HDL-apoC-II & $0.449^{c}$ & $0.490^{c}$ & 0.081 & $0.315^{b}$ & $0.752^{c}$ & & & & & \\
\hline Non-HDL-apoC-II & 0.180 & $0.465^{c}$ & -0.087 & 0.072 & $0.696^{c}$ & 0.050 & & & & \\
\hline ApoC-III & $0.283^{b}$ & $0.712^{c}$ & 0.075 & 0.098 & $0.760^{c}$ & $0.530^{c}$ & $0.568^{c}$ & & & \\
\hline HDL-apoC-III & $0.360^{c}$ & $0.681^{c}$ & 0.129 & 0.125 & $0.643^{c}$ & $0.517^{c}$ & $0.383^{c}$ & $0.789^{c}$ & & \\
\hline Non-HDL-apoC-III & 0.199 & $0.535^{c}$ & 0.035 & 0.041 & $0.602^{c}$ & $0.341^{b}$ & $0.523^{c}$ & $0.819^{c}$ & $0.293^{b}$ & \\
\hline ApoA-I & $0.312^{b}$ & 0.010 & $0.654^{c}$ & 0.144 & 0.040 & 0.035 & 0.033 & 0.169 & 0.197 & 0.067 \\
\hline ApoB & $0.845^{c}$ & $0.327^{b}$ & 0.005 & $0.835^{c}$ & $0.477^{c}$ & $0.452^{c}$ & $0.268^{a}$ & $0.344^{b}$ & $0.297^{b}$ & $0.296^{b}$ \\
\hline BMI & -0.039 & -0.041 & $-0.223^{a}$ & 0.022 & -0.057 & 0.030 & -0.088 & -0.075 & -0.029 & -0.100 \\
\hline Fasting glucose & $0.247^{a}$ & 0.097 & 0.100 & $0.224^{a}$ & 0.121 & 0.052 & 0.113 & 0.180 & 0.128 & 0.139 \\
\hline HOMA-IR (nondiabetic cohort) & -0.232 & 0.028 & -0.184 & -0.155 & -0.091 & 0.004 & -0.115 & -0.084 & 0.062 & -0.202 \\
\hline Adiponectin & 0.058 & -0.004 & $0.304^{b}$ & -0.017 & -0.065 & -0.107 & 0.073 & -0.002 & 0.092 & -0.056 \\
\hline Fat mass & 0.021 & -0.056 & -0.203 & 0.052 & -0.017 & 0.058 & -0.195 & 0.073 & 0.041 & -0.067 \\
\hline Energy intake & -0.106 & 0.151 & -0.080 & -0.212 & 0.090 & 0.099 & -0.025 & 0.093 & 0.206 & 0.039 \\
\hline
\end{tabular}

Apo, apolipoprotein; BMI, body mass index; HDL-C, high-density lipoprotein-cholesterol; HOMA-IR, homeostasis model assessment-insulin resistance; LDL-C, low-density lipoprotein-cholesterol; TC, total cholesterol; TG, triglycerides.

Data are Pearson correlation coefficients $\left({ }^{a} P<.05 ;{ }^{b} P<.01 ;{ }^{c} P<.001\right)$. Light gray $=$ positive correlations and dark gray $=$ negative correlations. 
Table 7 Multiple linear regression models predicting delta M12-M0 triglycerides evolution (final model after backward stepwise selection with a threshold for exclusion at $P<.05$ )

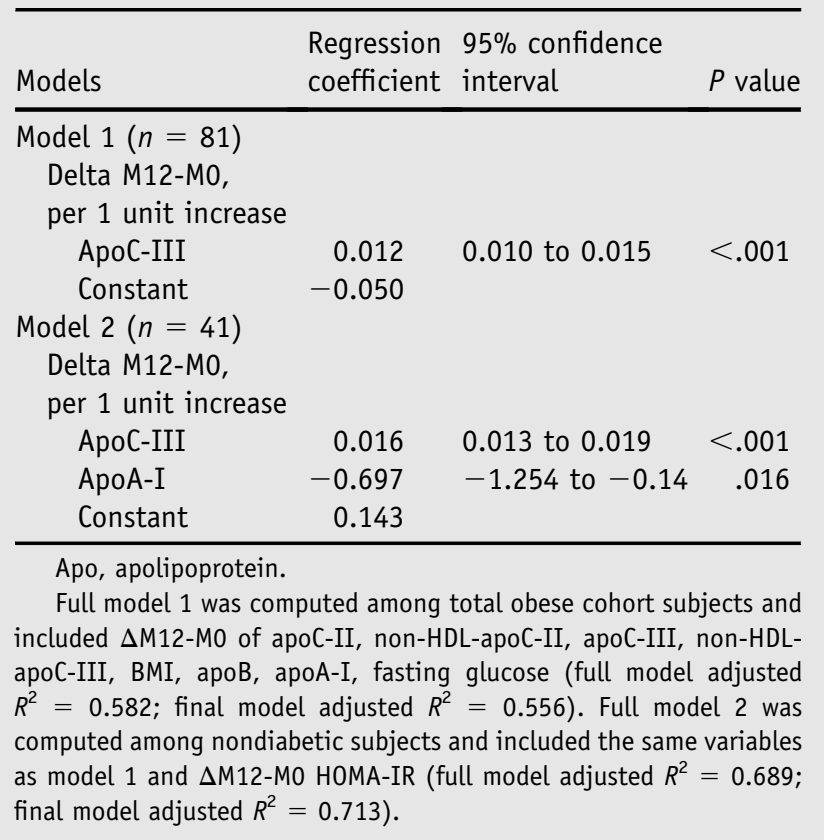

evolution of the distribution of apoC-III in non-HDL and HDL between M6 and M12 after surgery with a significant increase in HDL-apoC-III $(+4 \%)$ and a significant decrease in non-HDL-apoC-III $(-5 \%)$ in the total cohort. These changes led to a redistribution of apoC-III from non-HDL (decreasing from $55 \%$ to $50 \%$ ) to HDL (increasing from $45 \%$ to $50 \%$ ) fractions without a significant change in total plasma apoC-III concentrations. As already discussed, apoC-III concentrations play an important role in TRL metabolism but also in HDL metabolism. Indeed, it has been shown in nonobese subjects that HDL-apoC-III concentration was positively associated with HDL-apoA-I concentration and inversely with HDL-apoA-I FCR. ${ }^{59}$ Moreover, HDL-apoC-III production rate was correlated with HDL-apoA-I concentration and resident time in healthy subjects. ${ }^{60}$ In another study, HDL-apoC-III concentration was significantly elevated in centrally obese men compared with nonobese men and was significantly and directly correlated with production rate but also FCR of HDL-apoA-I in centrally obese men. Both VLDL apoCIII and HDL-apoC-III concentrations were positively associated with HDL-apoA-I hypercatabolism independently of BMI and insulin resistance. ${ }^{54}$ One can speculate that the quantitative and relative redistribution of apoC-III between TRL and HDL fractions after bariatric surgery, leading to an improved apoC-III distribution profile in lipoproteins, may have contributed to the improvement in TRL and HDL metabolism and finally to the reduction in plasma TG and the increase in HDL-C. Selective oligonucleotide antisense inhibition of apoC-IIII synthesis are currently being developed. This therapy causes a marked reduction in plasma apoC-III and TG concentration and an increase in HDL-C, highlighting the major role of apoC-III in TRL and HDL metabolism. ${ }^{61}$ Moreover, the efficiency of this treatment in TG reduction in familial chylomicronemia syndrome with LPL activity below $5 \%$ also underlines the role of apoC-III as a key regulator of LPL-independent pathways of TG metabolism. ${ }^{62}$

In conclusion, we have described, the evolution of apoCIII after bariatric surgery in humans. We showed, for the first time, marked reduction of total plasma apoC-III and non-HDL-apoC-III occurring after both GBP and SG. These quantitative changes were associated with a redistribution of apoC-III between TRL and HDL fractions consistent with a better lipid profile. Reduction of apoCIII and its lipoprotein redistribution after bariatric surgery may have implications in dyslipidemia improvement and could contribute to the reduction in cardiovascular morbidity and mortality that has been demonstrated after this effective treatment of obesity. Beyond a better understanding of the apoC-III role in the dyslipidemia of insulinresistant subjects, the present study could help the physicians to choose among other parameters the most appropriate bariatric surgery procedure depending on the lipid profile before surgery. Moreover, this study has confirmed apoC-III as an attractive clinical target in the fields of hypertriglyceridemia, atherogenic dyslipidemia, and cardiovascular disease.

\section{Acknowledgments}

The authors wish to thank Myriam Coffin for her technical assistance.

Funding: This work was supported by an AORC Excellence (AP-HM-2010).

Disclosure: All authors have participated in the research and/or article preparation. The paper has been read and approved by all authors.

Conflict of interest: The authors declare no conflict of interest.

\section{References}

1. Finucane MM, Stevens GA, Cowan MJ, et al, Global Burden of Metabolic Risk Factors of Chronic Diseases Collaborating Group (Body Mass Index).. National, regional, and global trends in body-mass index since 1980: systematic analysis of health examination surveys and epidemiological studies with 960 country-years and $9 \cdot 1$ million participants. Lancet. 2011;377:557-567.

2. Calle EE, Thun MJ, Petrelli JM, Rodriguez C, Heath CW. Body-mass index and mortality in a prospective cohort of U.S. adults. $N$ Engl J Med. 1999;341:1097-1105.

3. Adams KF, Schatzkin A, Harris TB, et al. Overweight, obesity, and mortality in a large prospective cohort of persons 50 to 71 years old. N Engl J Med. 2006;355:763-778.

4. Prospective Studies Collaboration, Whitlock G, Lewington S, Sherliker $\mathrm{P}$, et al. Body-mass index and cause-specific mortality in 900000 adults: collaborative analyses of 57 prospective studies. Lancet. 2009;373:1083-1096. 
5. Avramoglu RK, Basciano H, Adeli K. Lipid and lipoprotein dysregulation in insulin resistant states. Clin Chim Acta. 2006;368:1-19.

6. Adiels M, Olofsson SO, Taskinen MR, Borén J. Overproduction of very low-density lipoproteins is the hallmark of the dyslipidemia in the metabolic syndrome. Arterioscler Thromb Vasc Biol. 2008;28: $1225-1236$.

7. Duez H, Lamarche B, Uffelman KD, Valero R, Cohn JS, Lewis GF. Hyperinsulinemia is associated with increased production rate of intestinal apolipoprotein B-48-containing lipoproteins in humans. Arterioscler Thromb Vasc Biol. 2006;26:1357-1363.

8. Rashid S, Watanabe T, Sakaue T, Lewis GF. Mechanisms of HDL lowering in insulin resistant, hypertriglyceridemic states: the combined effect of HDL triglyceride enrichment and elevated hepatic lipase activity. Clin Biochem. 2003;36:421-429.

9. Lopez-Miranda J, Williams C, Lairon D. Dietary, physiological, genetic and pathological influences on postprandial lipid metabolism. Br J Nutr. 2007;98:458-473.

10. Ooi EMM, Barrett PHR, Chan DC, Watts GF. Apolipoprotein C-III: understanding an emerging cardiovascular risk factor. Clin Sci (Lond). 2008;114:611-624.

11. Bukberg PR, Le NA, Ginsberg HN, Gibson JC, Rubinstein A, Brown WV. Evidence for non-equilibrating pools of apolipoprotein C-III in plasma lipoproteins. J Lipid Res. 1985;26:1047-1057.

12. Nguyen MN, Chan DC, Dwyer KP, Bolitho P, Watts GF, Barrett PHR. Use of intralipid for kinetic analysis of HDL apoC-III: evidence for a homogeneous kinetic pool of apoC-III in plasma. J Lipid Res. 2006; 47:1274-1280.

13. Fredenrich A, Giroux LM, Tremblay M, Krimbou L, Davignon J, Cohn JS. Plasma lipoprotein distribution of apoC-III in normolipidemic and hypertriglyceridemic subjects: comparison of the apoCIII to apoE ratio in different lipoprotein fractions. J Lipid Res. 1997; 38:1421-1432.

14. Batal R, Tremblay M, Barrett PH, et al. Plasma kinetics of apoC-III and apoE in normolipidemic and hypertriglyceridemic subjects. $J$ Lipid Res. 2000;41:706-718.

15. Cohn JS, Patterson BW, Uffelman KD, Davignon J, Steiner G. Rate of production of plasma and very-low-density lipoprotein (VLDL) apolipoprotein C-III is strongly related to the concentration and level of production of VLDL triglyceride in male subjects with different body weights and levels of insulin sensitivity. J Clin Endocrinol Metab. 2004;89:3949-3955.

16. Hiukka A, Fruchart-Najib J, Leinonen E, Hilden H, Fruchart JC, Taskinen MR. Alterations of lipids and apolipoprotein CIII in very low density lipoprotein subspecies in type 2 diabetes. Diabetologia. 2005;48:1207-1215.

17. Béliard S, Nogueira JP, Maraninchi M, et al. Parallel increase of plasma apoproteins C-II and C-III in type 2 diabetic patients. Diabet Med. 2009;26:736-739.

18. Yao Z, Wang Y. Apolipoprotein C-III and hepatic triglyceride-rich lipoprotein production. Curr Opin Lipidol. 2012;23:206-212.

19. Ginsberg HN, Le NA, Goldberg IJ, et al. Apolipoprotein B metabolism in subjects with deficiency of apolipoproteins CIII and AI. Evidence that apolipoprotein CIII inhibits catabolism of triglyceride-rich lipoproteins by lipoprotein lipase in vivo. J Clin Invest. 1986;78: $1287-1295$.

20. Landis BA, Rotolo FS, Meyers WC, Clark AB, Quarfordt SH. Influence of apolipoprotein $\mathrm{E}$ on soluble and heparin-immobilized hepatic lipase. Am J Physiol. 1987;252:G805-G810.

21. Sehayek E, Eisenberg S. Mechanisms of inhibition by apolipoprotein C of apolipoprotein E-dependent cellular metabolism of human triglyceride-rich lipoproteins through the low density lipoprotein receptor pathway. J Biol Chem. 1991;266:18259-18267.

22. Clavey V, Lestavel-Delattre S, Copin C, Bard JM, Fruchart JC. Modulation of lipoprotein B binding to the LDL receptor by exogenous lipids and apolipoproteins CI, CII, CIII, and E. Arterioscler Thromb Vasc Biol. 1995;15:963-971.

23. Kawakami A, Aikawa M, Libby P, Alcaide P, Luscinskas FW, Sacks FM. Apolipoprotein CIII in apolipoprotein B lipoproteins enhances the adhesion of human monocytic cells to endothelial cells. Circulation. 2006;113:691-700.

24. Kawakami A, Aikawa M, Alcaide P, Luscinskas FW, Libby P, Sacks FM. Apolipoprotein CIII induces expression of vascular cell adhesion molecule-1 in vascular endothelial cells and increases adhesion of monocytic cells. Circulation. 2006;114:681-687.

25. Jensen MK, Rimm EB, Furtado JD, Sacks FM. Apolipoprotein CIII as a potential modulator of the association between HDLcholesterol and incident coronary heart disease. J Am Heart Assoc. 2012;1:1-10.

26. Sacks FM, Alaupovic P, Moye LA, et al. VLDL, apolipoproteins B, $\mathrm{CIII}$, and E, and risk of recurrent coronary events in the Cholesterol and Recurrent Events (CARE) trial. Circulation. 2000;102:1886-1892.

27. Onat A, Hergenç G, Sansoy V, et al. Apolipoprotein C-III, a strong discriminant of coronary risk in men and a determinant of the metabolic syndrome in both genders. Atherosclerosis. 2003;168:81-89.

28. Gervaise N, Garrigue MA, Lasfargues G, Lecomte P. Triglycerides, apo C3 and Lp B: C3 and cardiovascular risk in type II diabetes. Diabetologia. 2000;43:703-708.

29. Jørgensen AB, Frikke-Schmidt R, Nordestgaard BG, Tybjærg-Hansen A. Loss-of-function mutations in APOC3 and risk of ischemic vascular disease. N Engl J Med. 2014;371:32-41.

30. TG and HDL Working Group of the Exome Sequencing Project, National Heart, Lung, and Blood Institute, Crosby J, Peloso GM, Auer PL, et al. Loss-of-function mutations in APOC3, triglycerides, and coronary disease. $N$ Engl J Med. 2014;371:22-31.

31. Sjöström L, Narbro K, Sjöström CD, et al, Swedish Obese Subjects Study. Effects of bariatric surgery on mortality in Swedish obese subjects. N Engl J Med. 2007;357:741-752.

32. Sjöström L, Lindroos AK, Peltonen M, et al, Swedish Obese Subjects Study Scientific Group. Lifestyle, diabetes, and cardiovascular risk factors 10 years after bariatric surgery. $N$ Engl J Med. 2004;351: 2683-2693.

33. Padilla N, Maraninchi M, Béliard S, et al. Effects of bariatric surgery on hepatic and intestinal lipoprotein particle metabolism in obese, nondiabetic humans. Arterioscler Thromb Vasc Biol. 2014;34: 2330-2337.

34. Haute Autorité Santé guidelines. Obésité: prise en charge chirurgicale chez l'adulte, Available at: http://www.has-sante.fr/. Accessed January 2009

35. American Diabetes Association. Standards of medical care in diabetes-2014. Diabetes Care. 2014;37(Suppl 1):S14-S80.

36. Matthews DR, Hosker JP, Rudenski AS, Naylor BA, Treacher DF, Turner RC. Homeostasis model assessment: insulin resistance and beta-cell function from fasting plasma glucose and insulin concentrations in man. Diabetologia. 1985;28:412-419.

37. Buchwald H, Avidor Y, Braunwald E, et al. Bariatric surgery: a systematic review and meta-analysis. JAMA. 2004;292:1724-1737.

38. Pontiroli AE, Laneri M, Veronelli A, et al. Biliary pancreatic diversion and laparoscopic adjustable gastric banding in morbid obesity: their long-term effects on metabolic syndrome and on cardiovascular parameters. Cardiovasc Diabetol. 2009;8:37.

39. Benaiges D, Flores-Le-Roux JA, Pedro-Botet J, et al, Obemar Group. Impact of restrictive (sleeve gastrectomy) vs hybrid bariatric surgery (Roux-en-Y gastric bypass) on lipid profile. Obes Surg. 2012;22: 1268-1275.

40. Benetti A, Del Puppo M, Crosignani A, et al. Cholesterol metabolism after bariatric surgery in grade 3 obesity: differences between malabsorptive and restrictive procedures. Diabetes Care. 2013;36: $1443-1447$.

41. Bays HE, Jones PH, Jacobson TA, et al. Lipids and bariatric procedures part 1 of 2: scientific statement from the National Lipid Association, American Society for Metabolic and Bariatric Surgery, and Obesity Medicine Association: FULL REPORT. J Clin Lipidol. 2016;10:33-57.

42. Bays H, Kothari SN, Azagury DE, et al. Lipids and bariatric procedures Part 2 of 2: scientific statement from the American Society for Metabolic and Bariatric Surgery (ASMBS), the National Lipid 
Association (NLA), and Obesity Medicine Association (OMA). Surg Obes Relat Dis. 2016;12:468-495.

43. Chan DC, Watts GF, Redgrave TG, Mori TA, Barrett PHR. Apolipoprotein B-100 kinetics in visceral obesity: associations with plasma apolipoprotein C-III concentration. Metabolism. 2002;51:1041-1046.

44. Pont F, Duvillard L, Florentin E, Gambert P, Vergès B. Early kinetic abnormalities of apoB-containing lipoproteins in insulin-resistant women with abdominal obesity. Arterioscler Thromb Vasc Biol. 2002;22:1726-1732.

45. Hogue J-C, Lamarche B, Tremblay AJ, Bergeron J, Gagné C, Couture P. Evidence of increased secretion of apolipoprotein B-48containing lipoproteins in subjects with type 2 diabetes. J Lipid Res. 2007;48:1336-1342.

46. Wong ATY, Chan DC, Pang J, Watts GF, Barrett PHR. Plasma apolipoprotein B-48 transport in obese men: a new tracer kinetic study in the postprandial state. J Clin Endocrinol Metab. 2014;99:E122-E126.

47. Knudsen P, Eriksson J, Lahdenperä S, Kahri J, Groop L, Taskinen MR. Changes of lipolytic enzymes cluster with insulin resistance syndrome. Botnia Study Group. Diabetologia. 1995;38:344-350.

48. Pruneta-Deloche V, Sassolas A, Dallinga-Thie GM, Berthezène F, Ponsin G, Moulin P. Alteration in lipoprotein lipase activity bound to triglyceride-rich lipoproteins in the postprandial state in type 2 diabetes. J Lipid Res. 2004;45:859-865.

49. Vergès B. Pathophysiology of diabetic dyslipidaemia: where are we? Diabetologia. 2015;58:886-899.

50. Vergès B, Adiels M, Boren J, et al. Interrelationships between the kinetics of VLDL subspecies and HDL catabolism in abdominal obesity: a multicenter tracer kinetic study. J Clin Endocrinol Metab. 2014;99: 4281-4290.

51. Chen M, Breslow JL, Li W, Leff T. Transcriptional regulation of the apoC-III gene by insulin in diabetic mice: correlation with changes in plasma triglyceride levels. J Lipid Res. 1994;35:1918-1924.

52. Caron S, Verrijken A, Mertens I, et al. Transcriptional activation of apolipoprotein CIII expression by glucose may contribute to diabetic dyslipidemia. Arterioscler Thromb Vasc Biol. 2011;31:513-519.
53. Cohn JS, Tremblay M, Batal R, et al. Increased apoC-III production is a characteristic feature of patients with hypertriglyceridemia. Atherosclerosis. 2004;177:137-145.

54. Chan DC, Nguyen MN, Watts GF, Barrett PHR. Plasma apolipoprotein C-III transport in centrally obese men: associations with very lowdensity lipoprotein apolipoprotein B and high-density lipoprotein apolipoprotein A-I metabolism. J Clin Endocrinol Metab. 2008;93: $557-564$.

55. Taskinen MR, Adiels M, Westerbacka J, et al. Dual metabolic defects are required to produce hypertriglyceridemia in obese subjects. Arterioscler Thromb Vasc Biol. 2011;31:2144-2150.

56. Borén J, Watts GF, Adiels M, et al. Kinetic and related determinants of plasma triglyceride concentration in abdominal obesity: multicenter tracer kinetic study. Arterioscler Thromb Vasc Biol. 2015;35: 2218-2224.

57. Ooi EM, Chan DC, Hodson L, et al. Triglyceride-rich lipoprotein metabolism in women: roles of apoC-II and apo-CIII. Eur J Clin Invest. 2016;46:730-736.

58. Malmendier CL, Lontie JF, Grutman GA, Delcroix C. Metabolism of apolipoprotein C-III in normolipemic human subjects. Atherosclerosis. 1988;69:51-59.

59. Le NA, Gibson JC, Ginsberg HN. Independent regulation of plasma apolipoprotein C-II and C-III concentrations in very low density and high density lipoproteins: implications for the regulation of the catabolism of these lipoproteins. J Lipid Res. 1988;29:669-677.

60. Cohn JS, Batal R, Tremblay M, et al. Plasma turnover of HDL apoC-I, apoC-III, and apoE in humans: in vivo evidence for a link between HDL apoC-III and apoA-I metabolism. J Lipid Res. 2003;44: 1976-1983.

61. Gaudet D, Alexander VJ, Baker BF, et al. Antisense inhibition of apolipoprotein C-III in patients with hypertriglyceridemia. $N$ Engl $J$ Med. 2015;373:438-447.

62. Gaudet D, Brisson D, Tremblay K, et al. Targeting APOC3 in the familial chylomicronemia syndrome. $N$ Engl J Med. 2014;371: 2200-2206. 


\section{Appendix}

Supplementary Table 1 Presurgery (M0) antidiabetic and hypolipidemic treatments in the GBP and SG groups of obese subjects

\begin{tabular}{lcl}
\hline Treatments & GBP & SG \\
$(n=61)$ & $(n=71)$ \\
\hline Lifestyle counseling alone & 1 & 2 \\
Oral antidiabetic drugs & 16 & 8 \\
Insulin & 1 & 2 \\
Oral antidiabetic drugs and insulin & 6 & 3 \\
Statin & 12 & 7 \\
Fibrate & 0 & 2 \\
Fibrate and ezetimibe & 2 & 0 \\
\hline
\end{tabular}

GBP, gastric bypass; SG, sleeve gastrectomy.

Data are numbers of subjects treated with anti-diabetic and hypolipidemic treatment at pre-surgery (MO) in GBP and SG groups. 


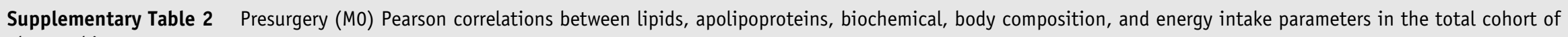
obese subjects

\begin{tabular}{|c|c|c|c|c|c|c|c|c|c|c|}
\hline Parameters & $\mathrm{TC}$ & TG & HDL-C & LDL-C & ApoC-II & HDL-apoC-II & Non-HDL-apoC-II & ApoC-III & HDL-apoC-III & Non-HDL-apoC-III \\
\hline \multicolumn{11}{|l|}{ TC } \\
\hline TG & $0.321^{c}$ & & & & & & & & & \\
\hline HDL-C & $0.294^{b}$ & $-0.255^{b}$ & & & & & & & & \\
\hline LDL-C & $0.819^{c}$ & 0.101 & 0.026 & & & & & & & \\
\hline ApoC-II & $0.424^{c}$ & $0.694^{c}$ & -0.017 & 0.154 & & & & & & \\
\hline HDL-apoC-II & $0.395^{c}$ & $0.521^{c}$ & 0.090 & 0.120 & $0.881^{c}$ & & & & & \\
\hline Non-HDL-apoC-II & $0.363^{c}$ & $0.702^{c}$ & -0.140 & $0.184^{a}$ & $0.837^{c}$ & $0.478^{c}$ & & & & \\
\hline ApoC-III & $0.458^{c}$ & $0.736^{c}$ & 0.036 & 0.150 & $0.773^{c}$ & $0.639^{c}$ & $0.662^{c}$ & & & \\
\hline HDL-apoC-III & $0.476^{c}$ & $0.712^{c}$ & 0.075 & 0.143 & $0.760^{c}$ & $0.703^{c}$ & $0.569^{c}$ & $0.874^{c}$ & & \\
\hline Non-HDL-apoC-III & $0.396^{c}$ & $0.605^{c}$ & -0.06 & 0.174 & $0.598^{c}$ & $0.416^{c}$ & $0.597^{c}$ & $0.877^{c}$ & $0.533^{c}$ & \\
\hline ApoA-I & $0.262^{b}$ & -0.127 & $0.737^{c}$ & 0.022 & -0.077 & -0.062 & -0.136 & 0.121 & 0.137 & 0.046 \\
\hline ApoB & $0.723^{c}$ & $0.510^{c}$ & -0.098 & $0.709^{c}$ & $0.461^{c}$ & $0.340^{c}$ & $0.470^{c}$ & $0.425^{c}$ & $0.417^{c}$ & $0.370^{c}$ \\
\hline BMI & 0.002 & 0.013 & -0.101 & 0.155 & -0.011 & 0.059 & 0.000 & -0.092 & -0.001 & -0.097 \\
\hline Fasting glucose & 0.142 & $0.377^{c}$ & -0.011 & 0.079 & $0.366^{c}$ & $0.257^{b}$ & $0.348^{c}$ & $0.344^{c}$ & $0.381^{c}$ & $0.214^{a}$ \\
\hline HOMA-IR (nondiabetic cohort) & -0.042 & 0.190 & $-0.293^{a}$ & 0.007 & 0.067 & 0.103 & 0.005 & 0.026 & 0.091 & -0.042 \\
\hline Adiponectin & $0.230^{b}$ & -0.148 & $0.500^{c}$ & 0.050 & -0.104 & 0.003 & -0.142 & 0.083 & 0.011 & 0.121 \\
\hline Fat mass & 0.089 & -0.190 & 0.200 & 0.090 & -0.162 & -0.133 & -0.044 & -0.174 & -0.086 & -0.155 \\
\hline Energy intake & -0.102 & 0.175 & $-0.210^{a}$ & $-0.233^{a}$ & $0.255^{a}$ & $0.235^{a}$ & 0.139 & $0.234^{a}$ & $0.232^{a}$ & $0.251^{a}$ \\
\hline
\end{tabular}

Apo, apolipoprotein; BMI, body mass index; HDL-C, high-density lipoprotein cholesterol; HOMA-IR, homeostasis model assessment-insulin resistance; LDL-C, low-density lipoprotein cholesterol; TC, total cholesterol; TG, triglycerides.

Data are Pearson correlation coefficients $\left({ }^{a} P<.05 ;{ }^{b} P<.01 ;{ }^{c} P<.001\right)$. Light gray $=$ positive correlations and dark gray $=$ negative correlations. 


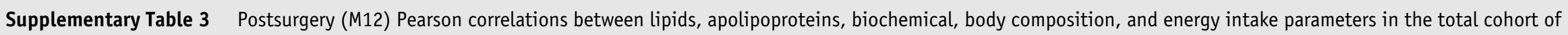
obese subjects

\begin{tabular}{|c|c|c|c|c|c|c|c|c|c|c|}
\hline Parameters & $\mathrm{TC}$ & TG & HDL-C & LDL-C & ApoC-II & HDL-apoC-II & Non-HDL-apoC-II & ApoC-III & HDL-apoC-III & Non-HDL-apoC-III \\
\hline \multicolumn{11}{|l|}{$\overline{\mathrm{TC}}$} \\
\hline TG & $0.336^{b}$ & & & & & & & & & \\
\hline HDL-C & $0.260^{a}$ & $-0.332^{b}$ & & & & & & & & \\
\hline LDL-C & $0.944^{c}$ & $0.228^{a}$ & 0.049 & & & & & & & \\
\hline ApoC-II & $0.412^{c}$ & $0.680^{c}$ & -0.013 & $0.315^{b}$ & & & & & & \\
\hline HDL-apoC-II & $0.378^{c}$ & $0.613^{c}$ & 0.013 & $0.288^{b}$ & $0.907^{c}$ & & & & & \\
\hline Non-HDL-apoC-II & $0.339^{b}$ & $0.571^{c}$ & -0.064 & $0.273^{b}$ & $0.836^{c}$ & $0.526^{c}$ & & & & \\
\hline ApoC-III & $0.443^{c}$ & $0.731^{c}$ & 0.068 & $0.246^{a}$ & $0.739^{c}$ & $0.691^{c}$ & $0.606^{c}$ & & & \\
\hline HDL-apoC-III & $0.478^{c}$ & $0.630^{c}$ & 0.203 & $0.305^{b}$ & $0.724^{c}$ & $0.729^{c}$ & $0.511^{c}$ & $0.867^{c}$ & & \\
\hline Non-HDL-apoC-III & $0.306^{b}$ & $0.660^{c}$ & -0.051 & 0.131 & $0.604^{c}$ & $0.539^{c}$ & $0.565^{c}$ & $0.908^{c}$ & $0.578^{c}$ & \\
\hline ApoA-I & $0.351^{c}$ & -0.054 & $0.799^{c}$ & 0.184 & 0.084 & 0.122 & -0.017 & $0.331^{b}$ & $0.390^{c}$ & 0.193 \\
\hline ApoB & $0.889^{c}$ & $0.424^{c}$ & -0.031 & $0.910^{c}$ & $0.478^{c}$ & $0.402^{c}$ & $0.434^{c}$ & $0.412^{c}$ & $0.382^{c}$ & $0.323^{b}$ \\
\hline BMI & -0.055 & 0.128 & -0.162 & -0.061 & 0.160 & 0.205 & 0.04 & 0.156 & 0.074 & 0.141 \\
\hline Fasting glucose & -0.017 & $0.370^{c}$ & $-0.303^{b}$ & 0.019 & $0.301^{b}$ & $0.325^{b}$ & $0.225^{a}$ & $0.236^{a}$ & $0.219^{a}$ & $0.213^{a}$ \\
\hline HOMA-IR (nondiabetic cohort) & $0.317^{a}$ & $0.503^{c}$ & $-0.378^{b}$ & $0.319^{a}$ & $0.451^{b}$ & $0.454^{b}$ & $0.374^{b}$ & $0.543^{c}$ & $0.413^{b}$ & $0.522^{c}$ \\
\hline Adiponectin & $0.200^{a}$ & $-0.250^{a}$ & $0.518^{c}$ & 0.113 & -0.095 & -0.144 & -0.040 & 0.076 & 0.126 & 0.046 \\
\hline Fat mass & 0.096 & -0.050 & 0.094 & 0.104 & 0.038 & 0.090 & -0.050 & 0.105 & 0.055 & 0.077 \\
\hline Energy intake & 0.055 & 0.089 & -0.146 & 0.053 & 0.030 & 0.093 & -0.033 & 0.057 & -0.029 & 0.088 \\
\hline
\end{tabular}

Apo, apolipoprotein; BMI, body mass index; HDL-C, high-density lipoprotein-cholesterol; HOMA-IR, homeostasis model assessment-insulin resistance; LDL-C, low-density lipoprotein-cholesterol; TC, total cholesterol; TG, triglycerides.

Data are Pearson correlation coefficients $\left({ }^{a} P<.05 ;{ }^{b} P<.01 ;{ }^{c} P<.001\right)$. Light gray $=$ positive correlations and dark gray $=$ negative correlations. 